\title{
Sinus pericranii in a neonate with the scalp hair tuft sign
}

\author{
Sagarika Ray
}

Department of Neonatal Medicine, Shrewsbury and Telford Hospital NHS Trust, Telford, UK

\section{Correspondence to Dr Sagarika Ray; sagarika.ray@nhs.net}

Accepted 16 November 2021

\section{DESCRIPTION}

A girl born by normal vaginal delivery at 34 weeks' gestation was noted to have a discrete midline scalp swelling from birth. This parieto-occipital lesion was non-tender, non-pulsatile and measured $10 \mathrm{~mm}$ in diameter. At 4 weeks of age, the lesion remained similar in size and had developed a tuft of hair over it, with a surrounding erythematous and nonindurated area (figure 1). The swelling temporarily increased in size in the supine position and resumed its usual size at other times. MRI (figure 2) showed a congenital anomaly of an elevated tentorium cerebelli with a tract connecting the distal end of the straight sinus with the superior sagittal sinus, which then connected with emissary veins in the scalp through a bony defect on T2 weighted images. The infant was diagnosed with sinus pericranii (SP) and no active intervention was advised by the paediatric neurosurgical team.

$\mathrm{SP}$ is a cranial venous anomaly where there is an abnormal communication between the intracranial dural sinuses and the extracranial venous structures, usually via a transosseous emissary vein. It is a low flow vascular malformation and most frequently involves the superior sagittal sinus. The hair tuft of the scalp (HTS) and hair collar sign (HCS) are cutaneous signs of neuroectodermal anomalies, such encephalocoeles, meningocoeles, dermoid cysts, membranous aplasia cutis, oculo-ectodermal syndrome, meningeal heterotopia and SP. Up to half also have a capillary vascular malformation and up to a third have skull bone defects with direct communication with the central nervous system. HCS is the more common manifestation. ${ }^{1}$ The coexistence of SP with HTS can be explained by the shared embryologic origin of the intracerebral and extracerebral venous system with cerebral and skull development. Interestingly, this infant developed the HTS and a capillary vascular malformation over the first few weeks after birth and presented with the typical history of the swelling increasing in size when supine, which is associated with a nonthrombosed SP.

Using the venous drainage pattern, SP can be classified into dominant or accessory types. ${ }^{2}{ }^{3}$ The dominant type is when the majority of the venous outflow from the brain occurs through the SP and active treatment through surgical excision should be avoided due to the risk of significant bleeding, venous infarction and sinus thrombosis. The accessory type is when a small portion of the venous outflow occurs through the SP and consideration can be given to treatment with excision or endovascular embolisation, especially if there are neurological

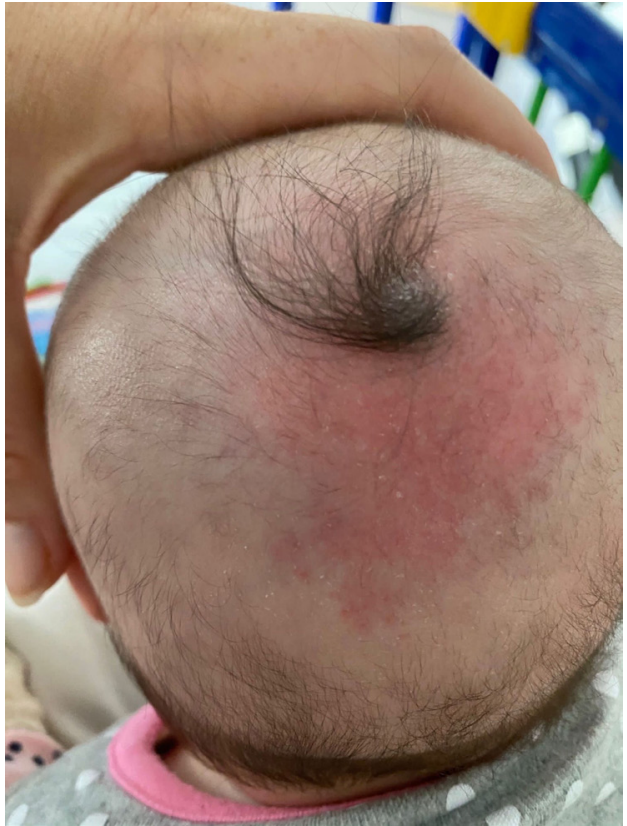

Figure 1 Neonate with scalp hair tuft sign.

symptoms, such as headache, or psychological concerns due to skull deformity and cosmetic issues, in later childhood. ${ }^{4}$ The natural history of SP is not fully understood but most have benign features and can be managed without intervention, with some regressing spontaneously. ${ }^{3}$ Digital subtraction angiography (DSA) may be useful to detect the location,

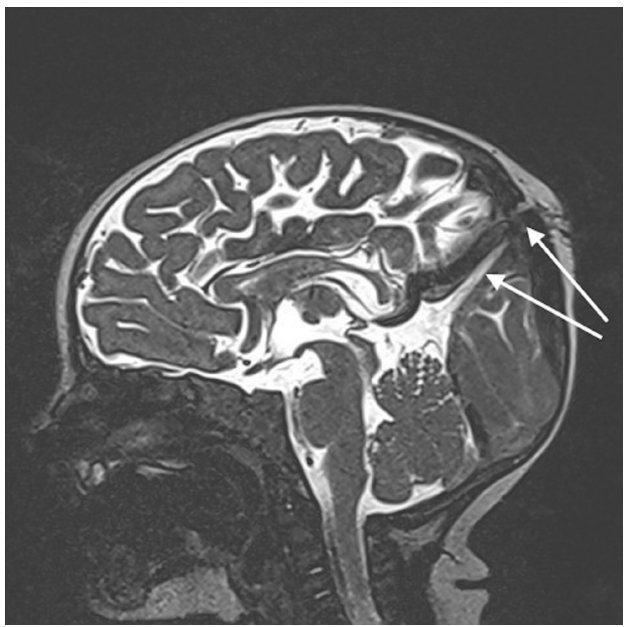

Figure 2 MRI head sagittal view T2 weighted image showing the elevated tentorium cerebelli and the tract connecting the intracranial dural sinuses with the extracranial venous structures through a bony defect. 
size and course of the venous anomaly, as well as provide information on the flow dynamics of the lesion. ${ }^{3}$

Contributors SR identified this patient, drafted, reviewed and approved the final manuscript.

\section{Learning points}

Ensure that cranial lesions in neonates are referred for further review and imaging to check for intracranial involvement, especially as there may be continuing changes to their external appearance over time.

- The nature and extent of neuroectodermal anomalies vary and cannot be predicted based on the cutaneous appearances of hair tuft of the scalp and hair collar sign alone. MRI is recommended as it has a high rate of detection of associated central nervous system and skull bone defects.

- Avoid excision of scalp lesions before a detailed evaluation has been undertaken through MRI or digital subtraction angiography, else there may be serious complications such as significant bleeding, venous infarction and sinus thrombosis.
Funding The authors have not declared a specific grant for this research from any funding agency in the public, commercial or not-for-profit sectors.

Competing interests None declared.

Patient consent for publication Consent obtained from parent(s)/ guardian(s).

Provenance and peer review Not commissioned; externally peer reviewed.

Case reports provide a valuable learning resource for the scientific community and can indicate areas of interest for future research. They should not be used in isolation to guide treatment choices or public health policy.

\section{ORCID iD}

Sagarika Ray http://orcid.org/0000-0002-4831-7280

\section{REFERENCES}

1 Bessis D, Bigorre M, Malissen N, et al. The scalp hair collar and tuft signs: a retrospective multicenter study of 78 patients with a systematic review of the literature. J Am Acad Dermatol 2017;76:478-87.

2 Gandolfo C, Krings T, Alvarez H, et al. Sinus pericranii: diagnostic and therapeutic considerations in 15 patients. Neuroradiology 2007;49:505-14.

3 Pavanello M, Melloni I, Antichi E, et al. Sinus pericranii: diagnosis and management in 21 pediatric patients. J Neurosurg Pediatr 2015;15:60-70.

4 Saba R, Senussi MH, Alwakkaf A. Sinus pericranii in a young adult with chronic headache. BMJ Case Rep 2013.

Copyright 2021 BMJ Publishing Group. All rights reserved. For permission to reuse any of this content visit

https://www.bmj.com/company/products-services/rights-and-licensing/permissions/

BMJ Case Report Fellows may re-use this article for personal use and teaching without any further permission.

Become a Fellow of BMJ Case Reports today and you can:

- Submit as many cases as you like

Enjoy fast sympathetic peer review and rapid publication of accepted articles

- Access all the published articles

- Re-use any of the published material for personal use and teaching without further permission

Customer Service

If you have any further queries about your subscription, please contact our customer services team on +44 (0) 2071111105 or via email at support@bmj.com.

Visit casereports.bmj.com for more articles like this and to become a Fellow 